\title{
Preparation of a Magnetic Composite Based on Cellulose Nanocrystals and Polyvinyl Alcohol and its Efficient Use for Removal of Nickel and Zinc Ions from Aqueous Solutions \\ Dawood, D. H. and M. A. Taher
}

Department of Agricultural Chemistry, Faculty of Agriculture, Mansoura University, Mansoura, 33516, Egypt.

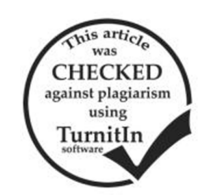

\begin{abstract}
Heavy metals are harmful ions and their removal from wastewater has attracted a growing attention amongst the scientific researchers in current decade. In this study, pea peels were used as precursor to purify cellulose nanocrystals (CNCs). Polyvinyl alcohol/ CNCs magnetic composite was developed as a novel bioadsorbent for adsorption of $\mathrm{Ni}$ (II) and $\mathrm{Zn}$ (II) ions from aqueous solutions. Results revealed that the adsorption efficiency of the examined ions by PVA/CNCs magnetic composite largely increased with increasing contact time. The equilibrium adsorption capacity was 4.19 and $4.00 \mathrm{mg} \mathrm{g}^{-1}$ for $\mathrm{Ni}$ (II) and $\mathrm{Zn}$ (II), respectively. The highest removal percentages for $\mathrm{Ni}$ (II) and $\mathrm{Zn}$ (II) were 83.86 and 80.13 , respectively at initial concentration of $10 \mu \mathrm{g} / \mathrm{ml}$. The FTIR and SEM $\mathrm{EDX}$ analysis were performed before and after $\mathrm{Ni}$ (II) and $\mathrm{Zn}$ (II) sorption on the PVA/cellulose beads, validating that the -OH groups played a chief role in sorption process. Finally, it could be concluded that PVA/cellulose magnetic composite is a promising adsorbent for removing $\mathrm{Ni}$ (II) and $\mathrm{Zn}$ (II) ions from wastewater.
\end{abstract}

Keywords: Pea peels, cellulose nanocrystals, PVA, magnetic composite, heavy metals.

\section{INTRODUCTION}

Heavy metal contamination is considered as one of the most harmful effects on environment and human health as a result of their extreme toxicity, non-biodegradability and accumulation on food chain sequence organisms (Nordberg et al., 2007). Metal-contaminated wastewater is generated yearly through various agricultural and industrial disposal processes (Mark et al., 2006). Remarkably, heavy metals adsorbents based on agricultural wastes are gaining much attention in last two decades on account that they provide advantages such as low-cost, abundance, highly effective (Mark et al., 2006). The main constituents of the agricultural waste resources include lignin, hemicelluloses, starch, sugars, proteins and lipids, containing different functional groups with a likely sorption capability for harmful metals (Bhatnagar et al., 2015). Cellulosic resources are being largely used as they deliver particular properties including non-toxicity, barrier function, edibility, biocompatibility, attracting appearance and low cost (Imran et al. 2010). Cellulose-based agricultural wastes are smoothly used in the removal of dangerous ions from wastewater. In this respect UlHaq et al. (2017) stated the efficacy of pea powdered peels to remove $\mathrm{Pb}$ and $\mathrm{Ni}$ from aqueous solutions. Different modified structures have been reported to increase sorption capacity of cellulosic wastes i.e. CNCs, biochars and magnetic composite (Bhatnagar and Sillanpää 2010; Khattak et al., 2017; Ahmad et al. 2018). Biodegradable polymers such as polyvinyl alcohol (PVA) could replace polyethylene or polypropylene to supply environmentally satisfying product and biodegradable composite materials. PVA is a water-soluble material involving many active hydroxyl groups which contribute to its hydrophilic character. It exhibited a good film-forming property with brilliant physicochemical stability (Koops et al., 1994). Interestingly, PVA/chitosan macro-porous has been reported to eliminate heavy metal from aqueous solutions (Li et al., 2011).

Nickel (Ni) salts are the prevalent reason of metal allergy among the publics seemed as contact dermatitis (Kasprzak et al., 2003). Zinc (Zn) is a critical element for a variety of life, but it is also highly toxic when used in high concentration. No available data in the literature about the usage of cellulose from pea waste in developing of a magnetic composite for the elimination of the previously mentioned harmful ions from wastewater. Therefore, the objective of this study is to prepare and characterize the magnetic composite resulting from the combination of PVA and pea by-product purified CNC, and to estimate the adsorption capacity of the resultant composite for the removal of $\mathrm{Ni}$ and $\mathrm{Zn}$ from aqueous solutions.

\section{MATERIALS AND METHODS}

\section{Pea peels samples}

Green pea by-product (GPP) was obtained from local market. Peels were washed with distilled water (D.W), air dried for $72 \mathrm{~h}$ and powdered to a uniform size.

\section{Chemical purification of cellulose}

Chemical purification of cellulose from pea peels was done using the scheme of (Kumar et al. 2013) with slight modifications as follows:-

Pea peels $(50.0 \mathrm{~g})$ were first de-fatted in a soxhlet unit using hexane for $6 \mathrm{~h}$. The solid phase was then acidified by sodium chlorite solution for the removal of lignin at $75^{\circ} \mathrm{C}$ for 90 minutes; this step was repeated for 4 times until the residue became white. The white residue was treated with $3 \%(\mathrm{w} / \mathrm{v}) \mathrm{NaOH}$ at $85-90^{\circ} \mathrm{C}$ for 120 minutes followed by filtration to eliminate hemicelluloses and other polysaccharides. The product was finally washed with D.W until the filtrate became neutral. Cellulose was dried at $105^{\circ} \mathrm{C}$ for $6 \mathrm{~h}$ and stored until used.

\section{Extraction of cellulose nanocrystals}

Extraction of cellulose nanocrystals (CNC) was performed by acid hydrolysis according the method of (Hudson et al., 2013) with slight modifications. The hydrolytic procedure was completed at $45^{\circ} \mathrm{C}$ for $60 \mathrm{~min}$ under the aid of stirring. One gram of purified cellulose was added to $12 \mathrm{~mL}$ of $\mathrm{H}_{2} \mathrm{SO}_{4} 9.17 \mathrm{M}$. At the end of the reaction, cold water was added to stop the hydrolytic reaction; the suspension was centrifuged for $15 \mathrm{~min}$ at $6000 \mathrm{ppm}$ to exclude the acidity. Then, the nascent precipitate was dialyzed against tap water until the neutral $\mathrm{pH}$ to remove soluble sugars, salts and non-reactive sulfate groups. Finally, the dialyzed suspension was considered as CNC of pea peel. 
Preparation of PVA/CNC magnetic composite.

PVA (1g) was dissolved in distilled water $(100 \mathrm{~mL})$ at $70{ }^{\circ} \mathrm{C}$ with continuous stirring for 2 hour (Zhu et al. 2014). Then CNC suspension was mixed with PVA solution and the blend was agitated again for $30 \mathrm{~min}$. Cations of $\mathrm{Fe}^{++}$(as $\mathrm{FeSO}_{4}$ ) and $\mathrm{Fe}^{+++}$(as $\left.\mathrm{FeCl}_{3}\right)(0.01 \mathrm{~mol}$ : $0.02 \mathrm{~mol}$ ) were supplemented into PVA/CNC mixture with continuous stirring for $40 \mathrm{~min}$. Then the resultant solution was introduced dropwise into a conical flask holding $150 \mathrm{~mL}$ sodium hydroxide solution $(8 \%, \mathrm{w} / \mathrm{v})$ to make the magnetic beads. Finally, solidification was performed by continuous stirring of the resultant alkali solution for 60 minutes, and then the beads were separated from the alkali solution and washed with $\mathrm{D} . \mathrm{W}$ until $\mathrm{pH} \sim 7$. The resultant composite was dried at $70{ }^{\circ} \mathrm{C}$ for $18 \mathrm{~h}$.

Characterization of PVA/CNC magnetic composite

$\mathrm{PVA} / \mathrm{CNC}$ magnetic composite was characterized by Vibrating Sample Magnetometer (VSM) (730T, Lakeshoper, America) (Hong et al .2008), Fourier Transform Infrared Spectroscopy (FTIR, Spectral Analysis Unit Chemistry Department Faculty of Science Mansoura University), scanning electron microscopy (JEOL JSM6510 LV, Japan, nanotechnology center of Mansoura University) and thermogravimetric analysis (TGA) (Ahuja et al., 2017) and differential scanning calorimeter (DSC) derivative studies.

Adsorption experiment and Analytical methods

The trials were carried out at room temperature by shaking $40 \mathrm{mg}$ of PVA/CNC magnetic composite with twenty $\mathrm{mL}$ solutions $\left(10,25\right.$ and $\left.50 \mathrm{mg} \mathrm{L}^{-1}\right)$ for $30 \mathrm{~h}$ at 140 rpm and $\mathrm{pH}$ 6.0. After adsorption, the magnetic composite was removed by filtration. For the kinetic trials, the initial concentration of $\mathrm{Zn}$ (II) and $\mathrm{Ni}$ (II) was ten $\mathrm{mg} / \mathrm{L}$, the contact time was 5,10,15, 20 and $25 \mathrm{~h}$ and the adsorbent mass was $40 \mathrm{mg}$. The concentrations of $\mathrm{Zn}$ (II) and Ni (II) were analyzed by atomic absorption spectrometer (Model SENS AA Dual, GBC Scientific equipments). The equilibrium adsorption capacity and the removal percentage can be calculated by the next equations:

$Q_{e}=\left(C_{0}-C_{e}\right) V / W(1)$ Removal \% $=\left[\left(C_{0}-C_{e}\right) / C_{0}\right] \times 100$ (2)

Where $Q_{e}(\mu \mathrm{g} / \mathrm{ml})$ is the equilibrium adsorption capacity; $C_{0}$ and $C_{e}$ $(\mu \mathrm{g} / \mathrm{ml})$ are the initial and equilibrium concentrations of $\mathrm{Ni}$ (II) and $\mathrm{Zn}$ (II), respectively; V (L) is the volume of the $\mathrm{Ni}$ (II) and $\mathrm{Zn}$ (II) solutions, and $\mathrm{w}$ (mg) is the mass of magnetic adsorbent.

\section{RESULTS AND DISCUSSION}

Magnetic composite was initially prepared using PVA and the purified CNC and then described. Lastly, adsorption behavior of the resultant magnetic composite for removal of $\mathrm{Ni}$ (II) and $\mathrm{Zn}$ (II) from aqueous media was investigated. Fig 1 shows physical appearances of pea peels (A), chemically purified cellulose (B), cellulose nanocrystals (CNC, C), ferrous and ferric salts solution (D) and prepared PVA/CNC magnetic composite (E). The schematic proposed structure of PVA/CNC bead is presented in Fig.2. The interacting hydroxyl groups on the surfaces of both CNC and PVA yield hydrogen bonds (Jayaramudu et al. 2018). Additionally, the higher quantity of CNC dispersed in the formed hydrogel, the higher is $\mathrm{CNC}$ aggregation as a result of the hydrophilic property of $\mathrm{CNC}$, causing the uniformly rough surface of the resultant composite (Jayaramudu et al. 2018).
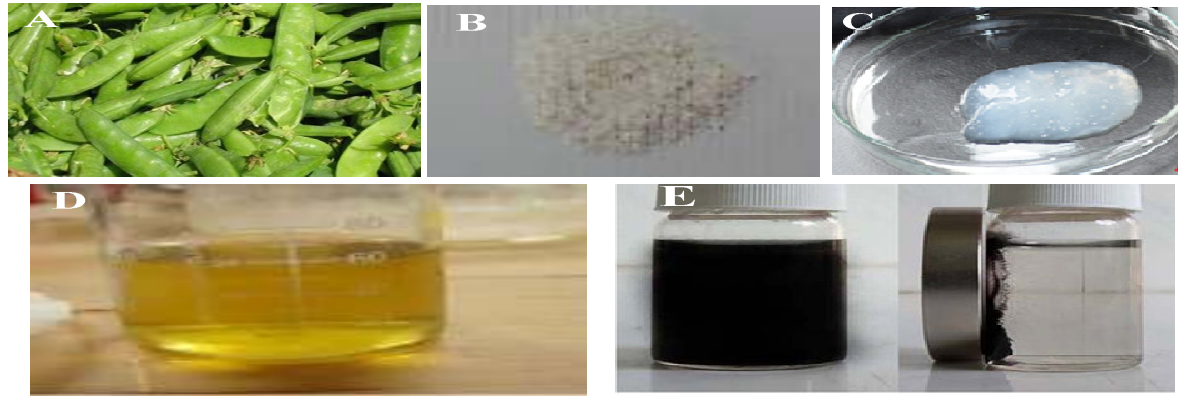

Fig. 1. Photo of (A) Pea peels (B) Chemically purified cellulose (C) Cellulose nanocrystals (D) $\mathrm{FeCl}_{3}$ and $\mathrm{FeSO}_{4}$ solution (E) Preparation the cross-linked of PVA/Cellulose nanocrystals magnetic composite.
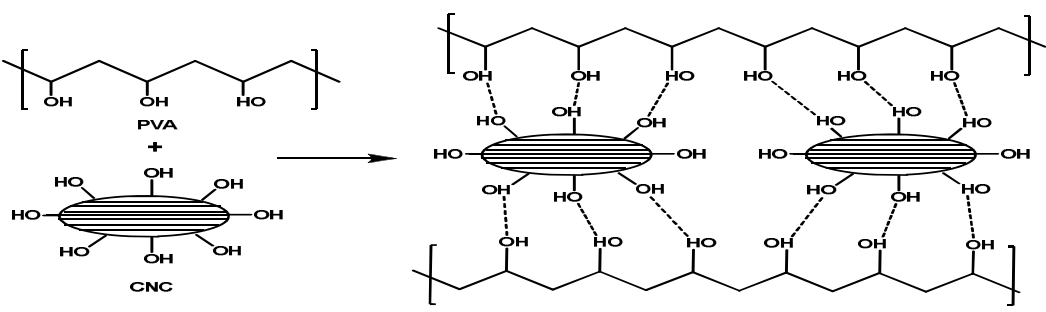

Fig. 2. Schematic proposed structure of PVA/CNC magnetic beads

\section{Characterization of PVA/CNC composite Magnetic properties}

To declare the magnetic property of the resultant nanocomposite as a utility of the applied magnetic field at $25{ }^{\circ} \mathrm{C}$, the beads were examined using VSM .The saturation magnetization of $\mathrm{PVA} / \mathrm{CNC}$ magnetic composite was calculated to be $19.748 \mathrm{emu} \mathrm{g}^{-1}$ (Fig 3), indicating that the resultant composite was superparamagnetic due to the occurrence of considerable content of iron oxide. So, PVA/cellulose magnetic composite can be simply removed with the aid of a magnetic force. Zhu et al (2014) found that the saturation magnetization for PVA/chitosan magnetic composite was 21.4 emu g $^{-1}$. 


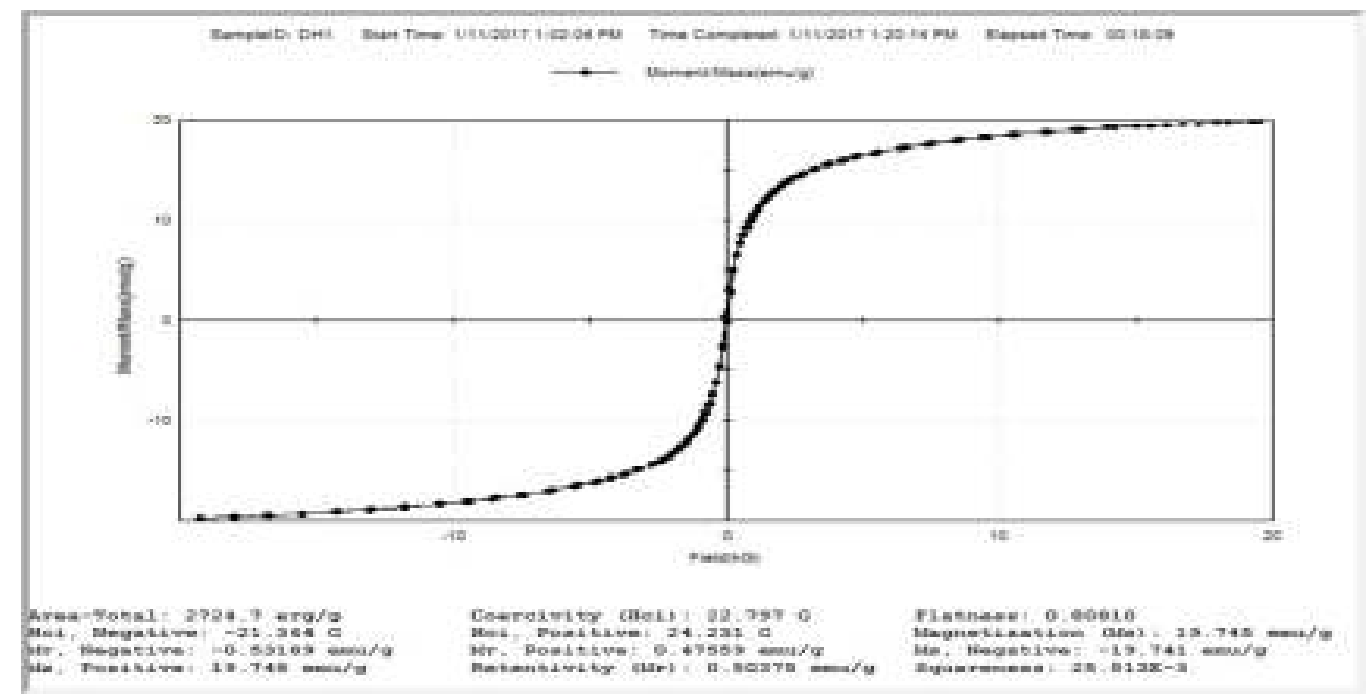

Fig. 3. Magnetic properties of prepared PVA/Cellulose magnetic composite

\section{Thermogravimetric analysis (TGA)}

TGA is a powerful procedure in estimating of the thermal stability of the materials (El-Sayed et al., 2011). In this trail, PVA/cellulose nanocrystal magnetic composite was decayed by heat, which breaks the bonds in the molecules. The derivative DTG indicates the equivalent rate of weight loss. DTG max is the temperature at which the thermolysis takes place at maximum rate. Thermal stability of various materials such as PVA/Cellulose magnetic composite could be assessed by determining their values of DTG max. Fig.4 presented the weight loss pattern on thermal decomposition of PVA/CNC magnetic composite that following multi-step thermal decomposition system as shown by (Rhim et al., 2013). TGA and DTG curves of PVA/Cellulose nanocrystals magnetic composite covered a temperature range from 120 to $650^{\circ} \mathrm{C}$. The initial weight loss was around $240^{\circ} \mathrm{C}$ as a result of the vaporization of absorbed moisture. The degradation phase at 240 and $340^{\circ} \mathrm{C}$ relates to degradation of PVA. The last step of degradation $\left(>615^{\circ} \mathrm{C}\right)$ corresponds to cellulose thermolysis (Elhefian et al., 2012).

Thermal stability studies on PVA/CNC magnetic composite were evaluated through DSC where heat of reaction was recorded. Enthalpy obtained from DSC (Fig 4) indicated good thermal stability for PVA/CNC magnetic composite. This shows that further energy is needed to break down the bonds (Watkins et al., 2015).

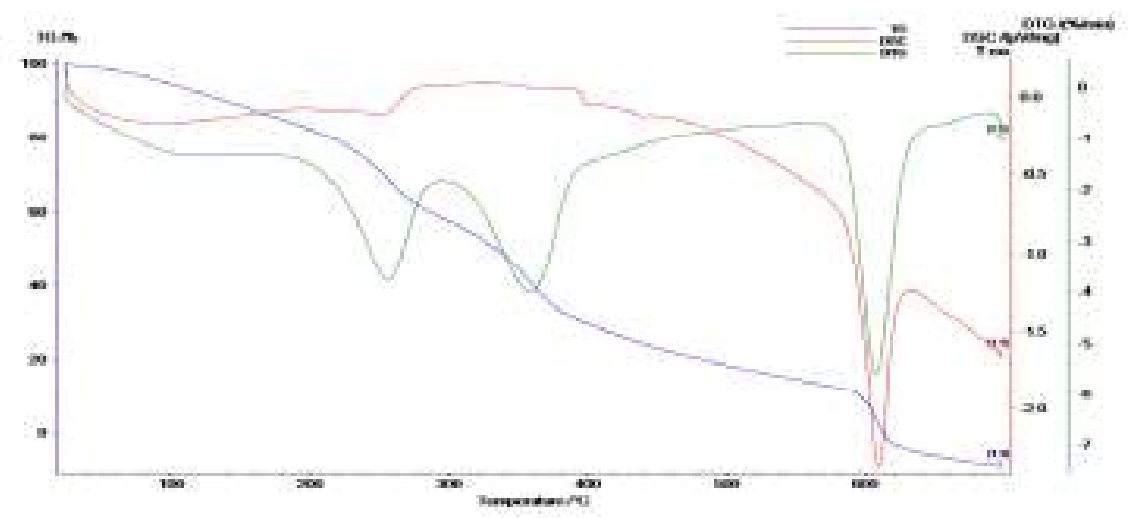

Fig. 4. TGA, DSC \& DTG curves of prepared PVA/Cellulose nanocrystal magnetic composite

FTIR Spectral Analysis

For confirmation of the structure of the prepared $\mathrm{PVA} / \mathrm{CNC}$ magnetic composite, FTIR spectra of $\mathrm{PVA} /$ cellulose magnetic was investigated before and after the adsorption of the examined ions (Fig, 5). The characteristic peaks of cellulose derivative are established as follows: the broad peak around $3418 \mathrm{~cm}^{-}$ ${ }^{1}$ relates to -OH stretching vibration, the peak at $2927 \mathrm{~cm}^{-}$ ${ }^{1}$ is qualified to $-\mathrm{CH}$ stretching vibration, the peak around $1628 \mathrm{~cm}^{-1}$ relates to of $\mathrm{C}=\mathrm{O}$. The bands in the range $1020-1100 \mathrm{~cm}^{-1}$ are assigned to pyranose skeleton (Yang et al., 2009). The peaks at $530-660 \mathrm{~cm}^{-1}$ are assigned to the occurrence of $\mathrm{Fe}-\mathrm{O}$, showing that $\mathrm{Fe}_{3} \mathrm{O}_{4}$ was successfully covered by PVA/cellulose nanocrystals. By matching the pictures before (Fig. 5A) and after adsorption (Fig. 5B), an extensive decline of adsorption intensity of the peak at $3418 \mathrm{~cm}^{-1}$ was clearly noticed. Peak shift was also observed from 3418 to $3424 \mathrm{~cm}^{-1}$. This means that $-\mathrm{OH}$ group participates in the adsorption route. The peak at $1020 \mathrm{~cm}^{-1}$ matching $\mathrm{C}=\mathrm{O}$ stretching was somewhat shifted to $1057 \mathrm{~cm}^{-1}$. From the FTIR description of the PVA/cellulose nanocrystals beads, it can be established that $-\mathrm{OH}$ is the main contributor for the adsorption of $\mathrm{Ni}$ (II) and $\mathrm{Zn}$ (II). 


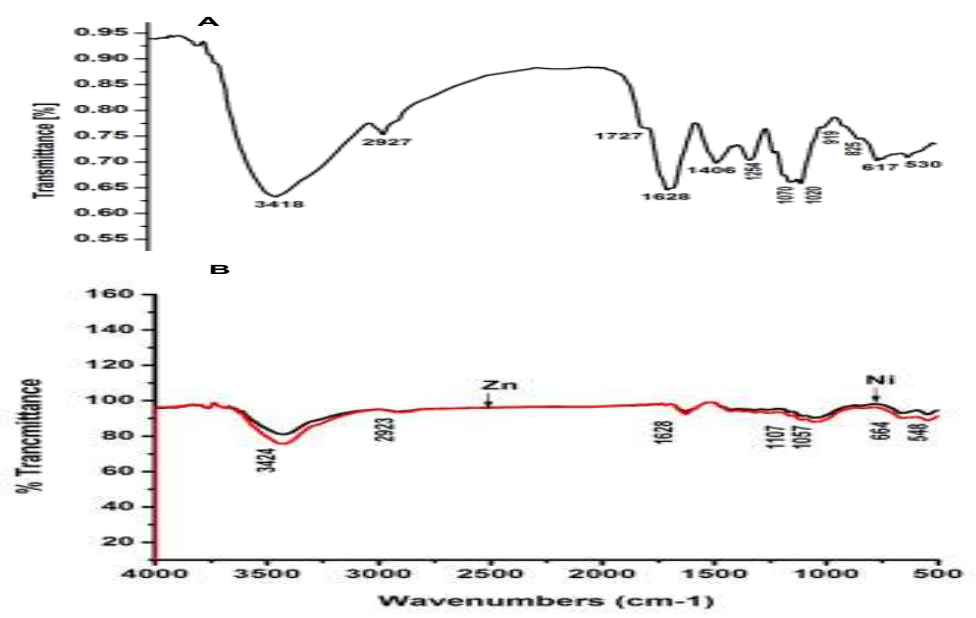

Fig. 5. The FTIR spectra of PVA/ CNC composite before (A) and after (B) Ni (II) and Zn (II) sorption.

The FTIR study of PVA/CNC magnetic composite before and after metal adsorption showed that the major complexing site is $-\mathrm{OH}$, since the atom of oxygen in $-\mathrm{OH}$ has a pair of electrons that can be added to proton or cation by a coordinated covalent bond. Ni (II) and $\mathrm{Zn}$ (II) ions have empty orbitals (Lewis acid), that receive electron pairs. As a result, the coordination conceivably designed by electron transfer (Zhu et al., 2014).

Table 1. The equilibrium adsorption capacity $\left(Q_{e}\right)$ and percentage of removal (Removal \%) of Ni (II) and $\mathrm{Zn}$ (II).using PVA/cellulose magnetic composite.

\begin{tabular}{lcccc}
\hline Metals & $\begin{array}{c}\text { Initial concentration } \\
(\boldsymbol{\mu g} / \mathbf{m l})\end{array}$ & $\begin{array}{c}\text { The concentration } \\
(\boldsymbol{\mu g} / \mathbf{m l}) \text { after Adsorption }\end{array}$ & $\begin{array}{c}\text { The equilibrium adsorption } \\
\text { capacity }\left(\mathbf{Q}_{\mathbf{e}}\right) \mathbf{~ m g} / \mathbf{g}\end{array}$ & $\begin{array}{c}\text { Removal } \\
\mathbf{\%}\end{array}$ \\
\hline \multirow{3}{*}{$\mathrm{Ni}(\mathrm{II})$} & 10 & $1.636 \pm 0.17$ & $4.180 \pm 0.08$ & $83.62 \pm 1.71$ \\
& 25 & $5.973 \pm 0.34$ & $9.516 \pm 0.17$ & $76.10 \pm 1.38$ \\
& 50 & $19.346 \pm 0.63$ & $15.663 \pm 0.30$ & $61.30 \pm 1.26$ \\
\hline \multirow{3}{*}{$\mathrm{Zn}$ (II) } & 10 & $1.993 \pm 0.22$ & $4.000 \pm 0.11$ & $80.06 \pm 2.20$ \\
& 25 & $7.156 \pm 0.15$ & $8.923 \pm 0.08$ & $71.37 \pm 0.62$ \\
& 50 & $20.180 \pm 0.62$ & $14.913 \pm 0.08$ & $59.64 \pm 0.62$ \\
\hline
\end{tabular}

\section{Adsorption experiment}

Nickel (Ni) salts can produce an increase of harmful effects on human health such as allergy and contact dermatitis (Kasprzak et al., 2003). Zinc (Zn) is a critical element for life, but it is also highly toxic when used in high concentration. Adsorption properties of PVA/CNC magnetic composite for removal of the tested ions from aqueous solutions were investigated. Forty $\mathrm{mg}$ of PVA/CNC magnetic adsorbent were added to $20 \mathrm{ml}$ of each of $\mathrm{Ni}$ (II) and $\mathrm{Zn}$ (II) solutions at different concentrations $(10,25$ and $50 \mathrm{ppm})$ under continuous stirring for $30 \mathrm{~h}$ at room temperature . Data presented in Table 1 indicate that the highest removal of Ni (II) and $\mathrm{Zn}$ (II) was reached at a concentration of $10 \mu \mathrm{g} / \mathrm{ml}$ with percentages of $83.62 \%$ and $80.06 \%$, respectively. It is also observed that the removal percentage of a heavy metal is inversely correlated with the heavy metal concentration. Our findings agreed in a large extent with that obtained by Li et al. (2011) who declared that PVA/chitosan could separately remove Malachite green (MG) and $\mathrm{Cu}^{2+}$. Additionally, (Monier and Abdel-Latif, 2012) developed a magnetic adsorbent based on phenylthiourea and chitosan as a proper treatment for wastewater containing harmful concentrations of heavy metals.

Fig.6 describes the adsorption efficacy of Ni (II) and $\mathrm{Zn}$ (II) by PVA/CNC magnetic composite which extensively increases with increasing contact time. At equilibrium (after 25h), adsorption capacities were 4.00 and $4.18 \mathrm{mg} / \mathrm{g}$ for $\mathrm{Zn}$ (II) and Ni (II), respectively (Table, 1). The adsorption route involved two stages: the first stage is rapid (till 15h); and the second is slow in which the adsorption equilibrium reached in $20 \mathrm{~h}$. In the rapid stage, surface of adsorption on PVA/CNC beads was not fully occupied with the heavy metal. The slowness of the second stage may be due to the diminution of the effective sites on the surface of the tested adsorbent. This finding agreed with that obtained by Sureshkumar et al. (2010) who found a rapid adsorption in the first $4 \mathrm{~h}$ of contact period and a slow stage in which the adsorption process reached equilibrium in the third day when tripolyphosphatechitosan composite was used in the treatment of uranium polluted solutions.

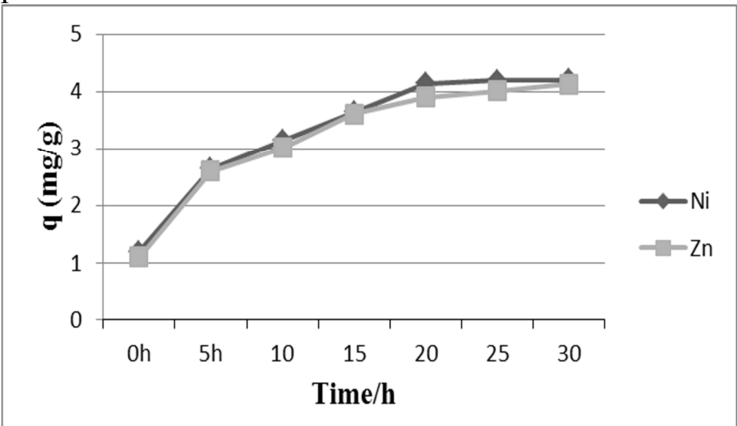

Fig. 6. Effect of contact time on $\mathrm{Ni}$ (II) and $\mathrm{Zn} \mathrm{(II)}$ sorption 
Generally, the highest adsorption capacities of $\mathrm{Ni}$ and $\mathrm{Zn}$ were attained at initial concentration of $50 \mu \mathrm{g} / \mathrm{ml}$ with the values of 15.66 and $14.91 \mathrm{mg} / \mathrm{g}$ adsorbent, respectively (Table, 1$)$. This result was moderately higher than that obtained by Ul-Haq et al. (2017) who stated that sorption capacity of $\mathrm{Ni}$ at initial concentration of $40 \mu \mathrm{g} / \mathrm{ml}$ from aqueous solutions ranged between $8.567 \mathrm{mg} / \mathrm{g}$ to $9.165 \mathrm{mg} / \mathrm{g}$ when pea peel was used as a natural sorbent. So it could be suggested that the developed magnetic nanocrystal composite from pea peels in this study increases their ability to adsorb the heavy metal from aqueous solutions.

Morphological characters of PVA/CNC magnetic composite before and after adsorption process was examined by SEM (Fig.7 A, B and C). It is noticed that the prepared magnetic composite is smooth surface wellshaped spheres with about $1 \mathrm{~mm}$ diameter. The adsorbed heavy metals on the surface of magnetic beads were studied by EDX. The EDX spectra of PVA/CNC bead before and after $\mathrm{Ni}$ (II) and $\mathrm{Zn}$ (II) adsorption is presented in Fig 7 A, B and C. Micro pores of magnetic composite in Fig $7 \mathrm{~B}$ and $\mathrm{C}$ were filled by metal ions and significant decreases in the surface roughness were occurred and so the heavy metal loaded magnetic composite (Fig 7 B and C) seemed to be smoother than that of non-treated composite (Fig 7A). The smoothness of PVA/CNC magnetic composite after sorption clarified the occurrence of Ni (II) and Zn (II) in the composite after adsorption. The occurrence of heavy metals on the surface of chitosan/silica gel beads was previously proven using SEM-EDX (Gandhi and Meenakshi, 2012).The interpretation of SEM-EDX and FTIR of PVA/cellulose magnetic composite before and after adsorption of $\mathrm{Ni}$ (II) and $\mathrm{Zn}$ (II) explained that -OH groups were involved in the adsorption of these metals.

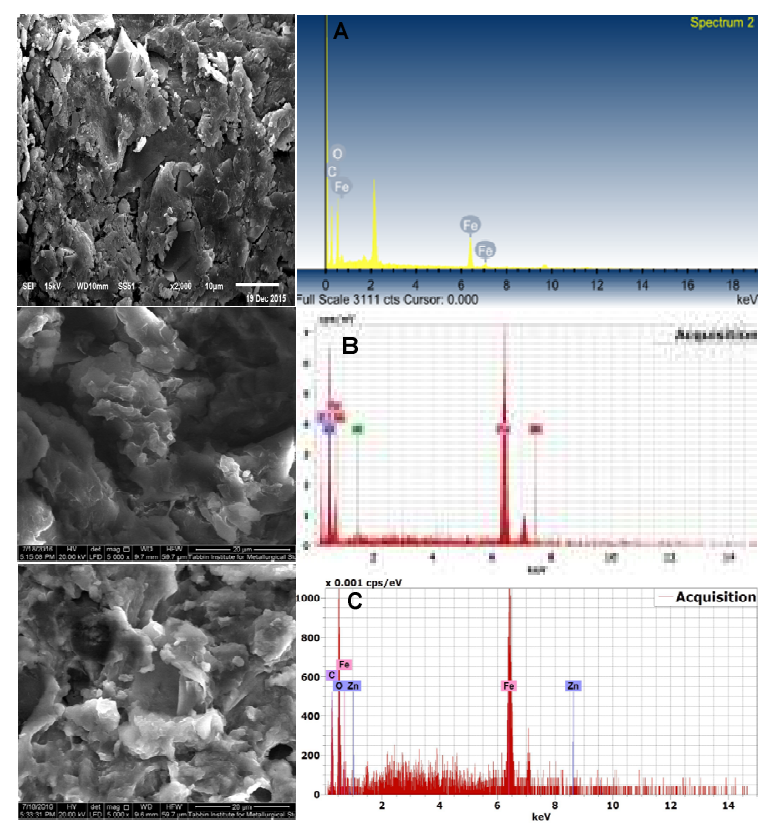

Fig. 7. The SEM-EDX spectra of PVA/cellulose nanocomposite before (A) and after (B), (C) $\mathrm{Ni}$ (II) and Zn (II) sorption.

\section{CONCLUSION}

Pea peels purified cellulose nano-crystals were used to prepare PVA/CNC magnetic composite which was entirely characterized and employed as an adsorbent for the removal of $\mathrm{Ni}$ (II) and $\mathrm{Zn}$ (II) from aqueous solutions. The maximum sorption capacities of the developed magnetic composite recorded were 15.66 and $14.91 \mathrm{mg} / \mathrm{g}$ for $\mathrm{Ni}$ (II) and $\mathrm{Zn}$ (II) from aqueous solutions, respectively. It could be elucidated that PVA/CNC magnetic composite is a good resource and eco-friendly adsorbent for removal of harmful ions from aqueous solutions.

\section{REFERENCES}

Ahmad, Z.; Gao , B. ; Mosa , A.;Yu, H.; Yin, X.; Bashir , A. ; Ghoveisi, H . and Wang, S. (2018). Removal of $\mathrm{Cu}(\mathrm{II}), \mathrm{Cd}(\mathrm{II})$ and $\mathrm{Pb}(\mathrm{II})$ ions from aqueous solutions by biochars derived from potassium-rich biomass. Journal of Cleaner Production, 180 $437 \mathrm{e} 449$.

Ahuja, D.; Kaushik, A. and Singh, M. (2017).Simultaneous extraction of lignin and cellulose nanofibrils from waste jute bags using one pot pre-treatment. International Journal of Biological Macromolecules, 107, 1294-1301.

Bhatnagar, A.; Sillanpää, M. and Witek-Krowiak, A.(2015). Agricultural waste peels as versatile biomass for water purification - a review . Chem. Eng. J., 270, 244-271.

Bhatnagar, A and Sillanpää, M. (2010). Utilization of agroindustrial and municipal waste materials as potential adsorbents for water treatment - a review. Chem. Eng. J., 157 , 277-296.

Elhefian, E.A.; Nasef, M.M. and Yahaya, A.H.(2012).Preparation and characterization of chitosan/agar blended films: part 2. Thermal, mechanical and surface properties. Journal of chemistry, 9, 2, 510-516.

El-Sayed, S.; Mahmoud, K.H.; Fatah, A.A. and Hassen, A. (2011). DSC, TGA and dielectric properties of carboxymethyl cellulose/polyvinylalcohol blends. Physica B 406, 4068-4076.

Gandhi, M.R. and Meenakshi, S. (2012). Preparation and characterization of La (III) encapsulated silica gel/chitosan composite and its metal uptake studies. J. Hazard. Mater. 203-204, 29-37.

Hong, R.Y.; Li, J.H.; Li, H.Z.; Ding, J.; Zheng, Y. and Wei, D.G. (2008). Synthesis of $\mathrm{Fe}_{3} \mathrm{O}_{4}$ nanoparticles without inert gas protection used as precursors of magnetic fluids. Journal of Magnetism and Magnetic Materials, 320, 16051614.

Hudson, A.S.; Wilson, P.F.N.; Noélio, O.D. and Daniel, P. (2013). Extraction and characterization of cellulose nanocrystals from corncob for application as reinforcing agent in nanocomposites. Industrial Crops and Products, 44, 427- 436 . 
Imran, M.; El-Fahmy, S.; Revol-Junelles, A. M. and Desobry, S. (2010). Cellulose derivative based active coatings: effects of nisin and plasticizer on physicochemical and antimicrobial properties of hydroxypropyl methylcellulose films. Carbohydrate Polymers 81, 219-225.

Jayaramudu , T.; Ko, H.U.; Kim, H. C.; Kim, J.W.; Muthoka, R. M. and Kim, J. (2018) . Electroactive Hydrogels Made with Polyvinyl Alcohol/Cellulose Nanocrystals.Materials,11,1615;doi:10.3390/ma11 091615.

Kasprzak, K.S.; Sunderman, F.W. and Salnikowa, K.(2003). Nickel carcinogenesis, Mutat. Res. Fund. Mol. M 533, 67-97.

Khattak, M. M.; Zahoor, M.; Muhammad, B.; Khan, F. A.; Ullah, R. and AbdEI- Salam, N. M. (2017).

Removal of Heavy Metals from DrinkingWater by Magnetic Carbon Nanostructures Prepared from Biomass. Journal of Nanomaterials . https://doi.org/10.1155/2017/5670371.

Koops, G.H.;Nolten, J.A.M.; Mulder, M.H.V.and Smolders, C.A. (1994). Selectivity as a function of membrane thickness: gas separation and pervaporation. J Appl Polym Sci 53, 1639-1651.

Kumar, A.; Negi, Y.S.; Bhardwaj, N.K. and Choudhary, V. (2013). Synthesis and characterization of cellulose nanocrystals PVA based bionanocomposite. Adv. Mat. Lett. 4, 8, 626-631.

Li, X.L.; Li, Y.F. and Ye, Z.F.(2011). Preparation of macroporous bead adsorbents based on poly (vinyl alcohol)/chitosan and their adsorption properties for heavy metals from aqueous solution. Chem. Eng. J. 178, 60-68.

Mark, S.S.; Crusberg, T.C.; DaCunha, C.M. and Dilorio, A.A. (2006). A heavy metal biotrap for wastewater remediation using poly- $\gamma$-glutamic acid. Biotechnol. Prog.,22, 523-531.
Monier, M. and Abdel-Latif, D.A. (2012). Preparation of cross-linked magnetic chitosan phenylthiourea resin for adsorption of $\mathrm{Hg}$ (II), Cd (II) and $\mathrm{Zn}$ (II) ions from aqueous solutions. J. Hazard. Mater. 209-210, 240-249.

Nordberg, G.F.; Fowler, B.A.; Nordberg, M. and Friberg, L.T. (2007). Handbook on the Toxicology of Metals, $3^{\text {rd }}$ ed., Elsevier, Amsterdam.

Rhim, J.; Wang, L. and Hong, S. (2013). Preparation and characterization of agar/silver nanoparticles composite films with antimicrobial activity. Food Hydrocolloids, 33, 2, 327-335.

Sureshkumar, M.K.; Das, D.;Mallia, M.B. and Gupta, P.C.(2010). Adsorption of uranium from aqueous solution using chitosan-tripolyphosphate (CTPP) beads. J. Hazard. Mater. 184, 65-72.

UlHaq, A.; Saeed, M.; Anjum, S.; Bokhari, H.T.; Usman, M. and Tubbsum, S. (2017). Evaluation of Sorption Mechanism of $\mathrm{Pb}$ (II) andNi (II) onto Pea (Pisumsativum) Peels .Journal of Oleo Science. doi: 10.5650/jos.ess17020.

Watkins, D.; Nuruddin, M.; Hosur, M.; Tcherbi-Narteh, A. and Jeelani, S. (2015). Extraction and characterization of lignin from different biomass resources, J. Mater.Res.Technol.4, 26-32.

Yang, L. and Zhang, L. M. (2009). Chemical structural and chain conformational characterization of some bioactive polysaccharides isolated from natural sources. Carbohydrate Polymers, 76, 349-361.

Zhu, Y.; Hu, J. and Wang, J. (2014). Removal of $\mathrm{Co}^{+2}$ from radioactive wastewater by polyvinyl alcohol (PVA)/chitosan magnetic composite. Progress in Nuclear Energy, 71, 172-178.

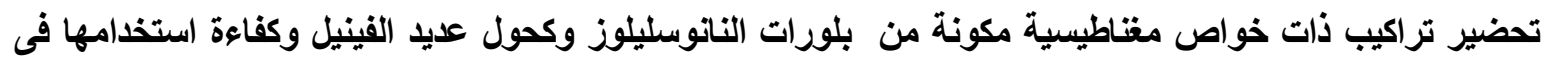

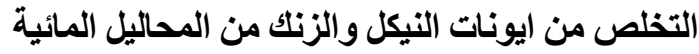

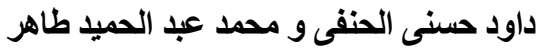

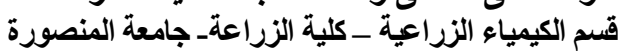

ان المعادن الثقيلة عناصر ضارة وهناك مزيدا من الاهتمام فى الوقت الحالي للعمل نحو التخلص من مثل هذه الملوثات البيئية من المياة

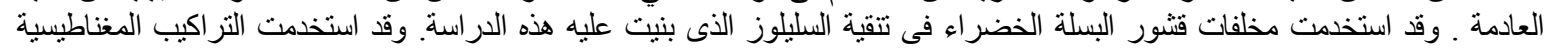

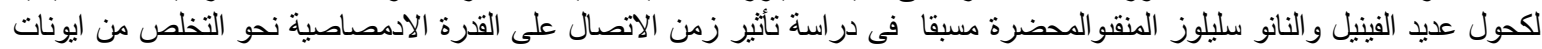

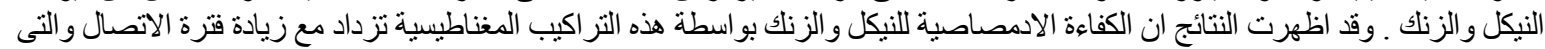

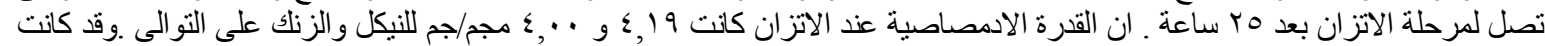

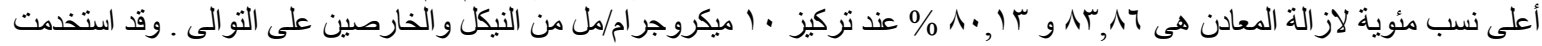

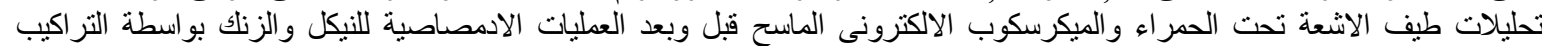

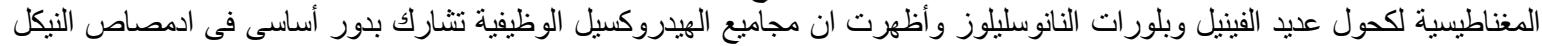

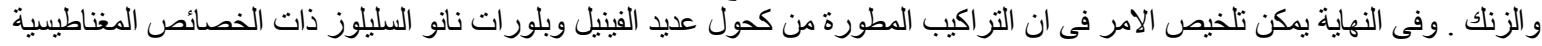

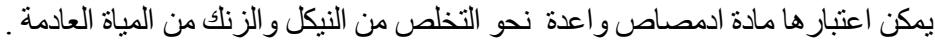

